\title{
Insightful learning in the laboratory: Some experiences from ten years of designing and using conceptual labs
}

\author{
Jonte Bernhard \\ Engineering Education Research Group, ITN, Campus Norrköping, Linköping University, \\ SE-60174 Norrköping, Sweden (jonbe@itn.liu.se)
}

\begin{abstract}
I describe a series of projects on the design and implementation of "conceptual labs" aimed at developing insightful learning, following work that began in 1994/95. The main focus has been on courses in mechanics and electric circuit theory. The approach taken in designing these innovative curricula can be described as "design-based research". A common feature in these learning environments is the use of technology as a tool to aid students' inquiry. In addition, systematic variation, based on the theory of variation, has been introduced into the design of the assigned tasks. Results from conceptual inventories have demonstrated the success of conceptual labs. In the later projects we used video recording to study students' courses of action in labs. I describe how these studies have provided insights into conditions that are critical for learning and how these insights have helped me and co-workers to make further improvements to learning environments.
\end{abstract}

Keywords: Engineering education research, variation theory, design-based research, lab-work, learning environment

\section{Introduction}

In both engineering and physics education, a common objective is that students should learn to use theories and models in order to understand the relation between theories and models, and objects and events, and to develop holistic, conceptual knowledge. This is often seen as the fundamental purpose of lab work (e.g. Psillos and Niedderer 2002). During lab-work, students are expected to use, or learn to use, symbolic and physical tools (such as concepts, theories, models, representations, inscriptions, mathematics, instruments and devices) in order both to understand the phenomena being studied, and to develop the skills and abilities to use the tools themselves. Rorty $(1991$, p. 1) has formulated a view of knowledge within the pragmatism tradition as being not "a matter of getting reality right, but a matter of acquiring habits of action for coping with reality". In a similar vein, Marton et al. (2004, p. 5) see knowledge as a "capability of handling novel situations in powerful ways". These views seem natural to engineering educators since "technology [concerns itself] with what is to be" (Skolimowski 1966, p. 375, emphasis in the original).

At a physics education conference at Tufts University, the following conclusion was stated as an important finding and an important aim:

"Connections among concepts, formal representations, and the real world are often lacking after traditional instruction. Students need repeated practice in interpreting physics formalism and relating it to the real world" (emphasis in the original, McDermott 1997).

In similar vein, Vince and Tiberghien (2002, p. 51) state that "establishing relevant relations between the physics model and the observable objects and events is a very difficult task". However, research by our group and other authors has shown that these connections do not arise spontaneously in students' minds. Acquiring a conceptual understanding of mechanics, for example, has proven to be one of the most difficult challenges faced by students. This can be seen in our data, displayed in Figure 7a, showing that most students participating in a traditionally taught university level course had not acquired a Newtonian understanding of 
mechanics at the end of the course (See also, for example, Laws 1997a, McDermott 1997, McDermott and Redish 1999, Thornton 1997).

In recent decades there have been many attempts to create learning environments that are not only exploratory, but also direct students' attention towards relevant concepts and phenomena in a process known as guided discovery (Hammer 1997, Novak 1979) or interactive-engagement (Hake 1997). Labs adopting these processes foster an inquiry-driven learning environment in which students are guided in their inquiry by carefully designed instructions, technology, and teacher support. Examples include curricular projects such as Workshop Physics (Laws 1997a, 1997b), RealTime Physics (Sokoloff et al. 2007, Sokoloff et al. 1998), and Tools for Scientific Thinking (Thornton 1987). A common feature of these projects is that they make use of a technology called probe-ware or Microcomputer-Based Labs (MBL).

Probe-ware systems were introduced into physics teaching almost three decades ago and are good examples of the use of interactive technology in physics education (Tinker 1996). They consist of a sensor or a probe connected to a computer, which analyses data collected by the probe, and transforms experimental data directly into a graph on the computer screen. When using probe-ware, students can perform experiments using a range of different sensors to gather data on variables such as force, motion, temperature, light or sound. The simultaneous collection, analysis and display of experimental data is sometimes referred to as real-time graphing. The immediacy of this technology allows the design of labs that foster a functional understanding of physics most effectively (Hake 1997, Thornton 1996, 1997, Tinker 1996).

Inspired by the success of the curricula mentioned above, in 1994/95 I started a series of projects focused on the design and implementation of 'conceptual labs' aimed at developing insightful learning. A 'conceptual lab' is one that helps students to develop fruitful ways of linking concepts and models to objects and events (Bernhard 2003). Furthermore, it is a place of inquiry, where students" "ways of seeing or experiencing ... the world [are developed]"; i.e. the lab is an arena for further learning and not simply for the confirmation of theories and formulas that have already been taught in lectures. The main focus of the work has been on courses in mechanics and electric circuit theory. The projects have involved university courses for students of engineering, and students enrolled in teacher training.

Some of the results from these projects have been reported before, but mainly as conference papers and reports presenting experiences from a single project. This paper presents an overview of, and a synthesis of common findings from, these projects not presented before. The possibility of fostering insightful learning in student laboratories by using carefully designed activities based on education research and theoretically informed development is demonstrated. Below, I describe some aspects of the methodology for designing conceptual labs with examples of some tasks $(\S 2)$, the methodology for evaluating the learning process and learning results $(\S 3)$, and a brief history of, and the learning results achieved, using conceptual labs (§4). Finally in section 5, a short discussion and conclusion are presented.

\section{Methodology for designing conceptual labs}

\subsection{Variation theory}

The approach used in our development of conceptual labs was, as mentioned above, originally inspired by the pedagogical approaches applied in RealTime Physics (Sokoloff et al. 2007, Sokoloff et al. 1998) and research in physics education (McDermott and Redish 1999).

According to this research, certain concepts and topics are difficult to learn, or are 
misconceived, by most students (See Figure 7a). Hence, in the selection and design of tasks special attention should be given to critical features of the subject matter to be learned, as is done, for example, in RealTime Physics. The pedagogical principles behind RealTime Physics are only briefly described in the literature and are commonly described in terms such as "[incorporating] a learning cycle consisting of prediction, observation, comparison, analysis and quantitative experimentation" (Sokoloff et al. 2007, p. S86). However, I claim (Bernhard 2009a) that the design of many tasks in RealTime Physics can be understood in terms of the principles proposed by Variation theory (cf. Runesson 2006).

Variation theory, developed by Marton and co-workers (Bowden and Marton 1998, Marton and Booth 1997, Marton and Tsui 2004), provides an explanatory framework describing the conditions required for learning. Central to this theory is the notion that we learn through experiencing differences, rather than recognising similarities. Central concepts in variation theory are discernment, simultaneity and variation. Learning is seen as the process of developing certain capabilities and values that enable the learner to handle novel situations effectively. Powerful ways of acting emerge from powerful ways of seeing. Thus, aspects that can be discerned by the observer determine how something is seen in a particular way. People discern certain aspects of their environment by experiencing variation. When one aspect of a phenomenon or an event varies, while one or more aspects remain the same, the one that changes is the one that will be discerned. One of the main themes of variation theory is that the pattern of variation inherent in the learning situation is fundamental to the development of certain capabilities. It should be noted that 'discerning' is not the same as being 'being told'.

Experiencing variation amounts to experiencing different instances simultaneously. This simultaneity can be either diachronic (experiencing, at the same time, instances that we have encountered at different points in time) or synchronic (experiencing different co-existing aspects of the same thing at the same time). In section 2.3 below, I present examples of tasks designed in line with variation theory using probe-ware as mediating tools.

\subsection{Mediating tools}

According to variation theory an important condition for learning is that students are able to focus on the object of learning and discern its critical features An essential part of a lab is the use of different kinds of instrumentation to study an experimental set-up or natural phenomenon. Thus, an human experience in the laboratory is a mediated experience (Cole 1996, pp. 117-122, Vygotsky 1978, especially pp. 38-40 and pp. 52-57) and the relationship can schematically be expressed as (e.g. Ihde 1979, 1991): Human $\Leftrightarrow$ Instrument $\Leftrightarrow$ World.

In science, instruments do not merely "mirror reality", but mutually constitute the reality investigated. This technology can be used to place some aspects of reality in the foreground, others in the background, and to make certain aspects visible that would otherwise be invisible or difficult to perceive (e.g. Ihde 1979, 1991, 2009). Technology can thus be used in conceptual labs to frame our experience or give shape to the figurebackground relationship (Bernhard 2007, 2009b) and hence bring critical features into the focal awareness of students and highlight any relevant variation. 


\subsection{Examples of tasks designed using variation theory}

In this section I examine three examples of tasks used in different conceptual labs, and focus on an analysis of the tasks in terms of discernment, simultaneity and variation.
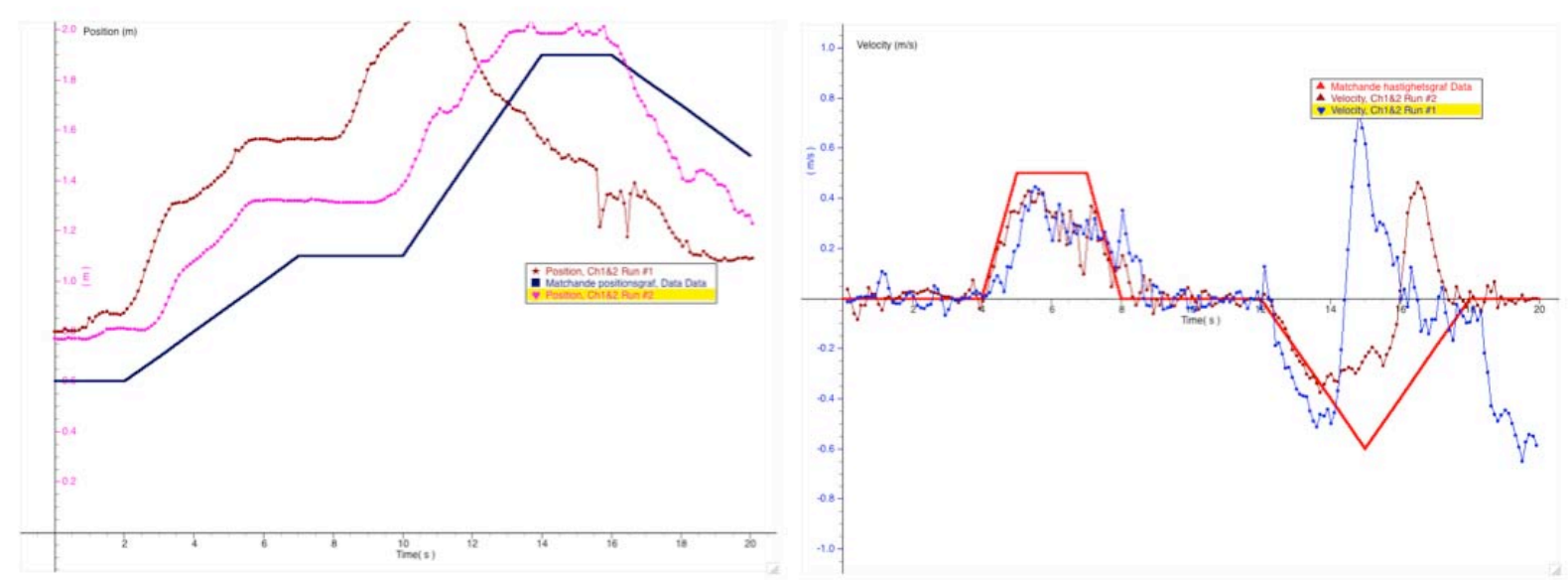

FIGURE 1. An example of a task that students attempt in a kinematics-lab. To the left is an $s(t)$ - and to the right a $v(t)$-graph with curves that the students are asked to recreate, together with experimental graphs produced by students.

Example 1: This example is one of the earlier tasks in a typical conceptual-lab in mechanics. Students are asked to walk a trajectory that matches a given velocity-time graph. While moving, the participant and the other learners can see the experimental graph being produced in real-time (see Figures 1 and 2). Prior to this activity, students have solved tasks involving position-time graphs. Figure 2 shows an excerpt from the task presented in Figure $1 \mathrm{~b}$. 


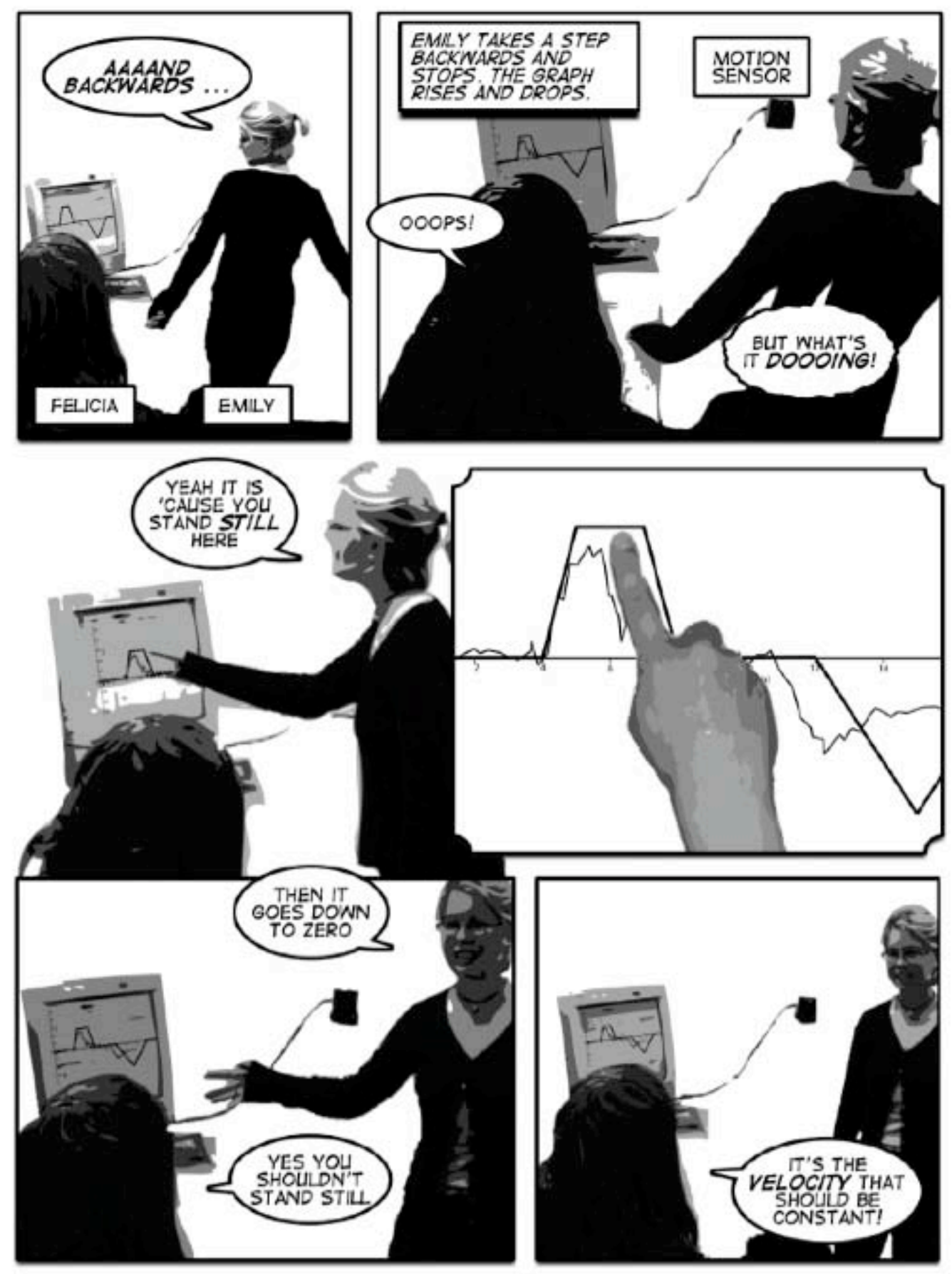

FIGURE 2. Drawings, based on video recordings, to illustrate students' courses of action. This illustration is from the thesis of Oskar Lindwall (2008) using data collected from a conceptual lab in mechanics.

In this task, technology brings velocity to the fore: i.e. it enters into the focal awareness of students. During the events represented in Figure 2, Emily and Felicia realise the difference between position and velocity versus time graphs, i.e. they develop a more differentiated understanding of the physical concepts of motion. Other features of the situation, physical as well as non-physical, are not highlighted, i.e. some discernment has already occurred. It is also important that velocity is established as having a relationship with objects and events in the world. In order to complete the assignment, students have to understand this; they must also make important conceptual distinctions. Figure 1b shows data 
from students who struggle with the meaning of negative velocity and especially highlights data from those for whom negative velocity with a decreasing magnitude was, incorrectly, translated into a change in their direction of motion.

This task involves synchronic as well as diachronic simultaneity. The comparison in real-time between the experimental graph and the previously drawn graph is an example of synchronic simultaneity. The realisation, as displayed in Figures 1-2, is an example of diachronic simultaneity.
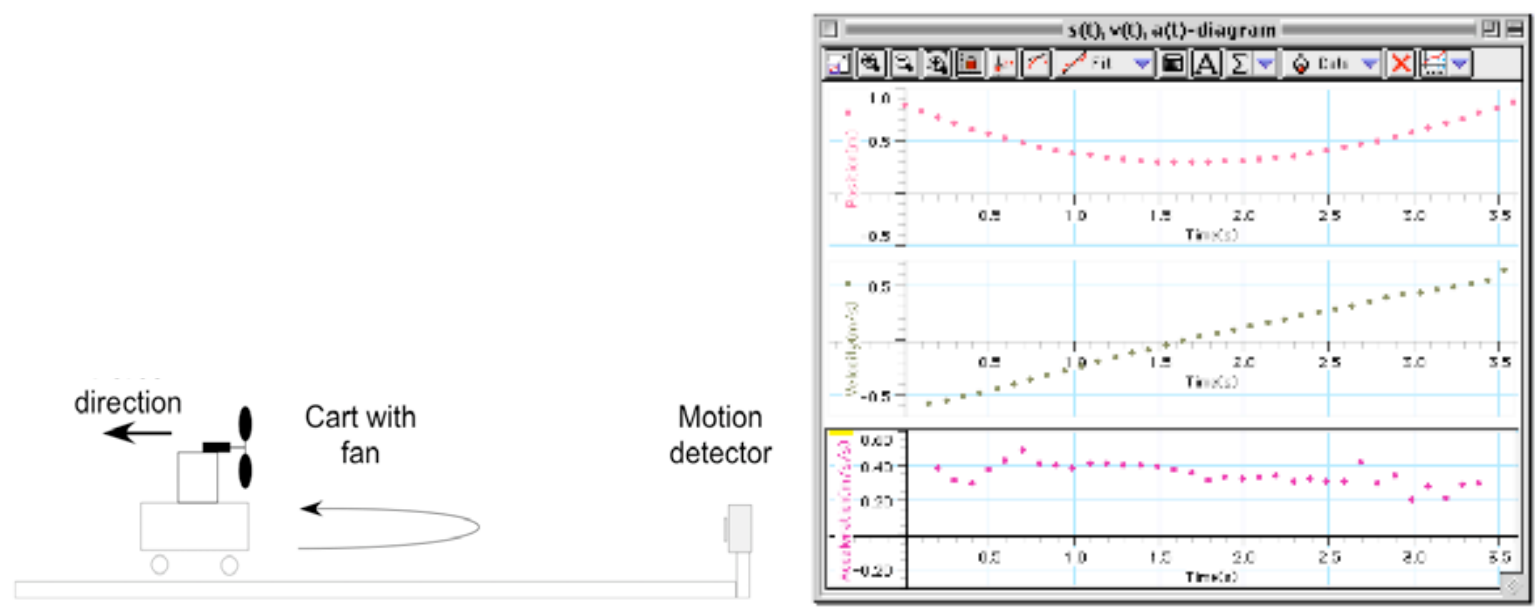

FIGURE 3. A typical setup in an MBL-experiment. A low-friction cart is pushed towards a motion sensor. A fan unit attached to the cart provides an approximately constant force in the opposite direction to the initial movement and, thus, the cart's direction of motion. The results are shown to the right. The results show that acceleration is not zero at the turning point. Note that the fan unit provides a visible source of the force.

Example 2: Acceleration with zero velocity. In this activity students monitor the motion of a cart propelled by a fan that provides an almost constant "visible" force and, hence, almost constant acceleration (see Figure 3a). In this task the students should give the cart an initial push in the opposite direction to that in which the force of the fan is acting, so that the cart will slow down and reverse its direction of motion. They do this after studying the motion of the cart without reversing its direction, but with acceleration in different directions. Students are first asked to observe the motion of the cart (without measuring it) and then to sketch their predictions of how the motion will be represented by position-time, velocity-time and acceleration-time graphs. After they have made their predictions the motion of the cart is once more observed and this time the probe-ware equipment is used to measure the motion, and simultaneously display it as a graph (a typical graph is shown in Figure $3 b$ ). To make accurate predictions, not only do the differences between position, velocity and acceleration have to be discerned, but also the relationships between these concepts. Velocity and position vary, but students have to recognise that the acceleration is constant, and that a zero velocity does not imply that the acceleration is zero - as is commonly believed. Asking the students to make predictions before the experiment is performed, and comparing the outcome with their predictions, facilitates comparisons between their thinking and reality. We could regard any discrepancy as a variation in the space of thinking models. Students thus have the opportunity to discriminate between different "models" and see which is the most powerful. 
Example 3: In this task (taken from a course in electric circuit theory) students study six systematically varied transfer-functions:

$$
\begin{array}{lll}
G_{a}(s)=\frac{3 s+5}{s^{2}+2 s+5} & G_{b}(s)=\frac{3 s+5}{s^{2}+2 s+1} & G_{c}(s)=\frac{3 s+5}{s^{2}+2 s+0.75} \\
G_{d}(s)=\frac{5}{s^{2}+2 s+5} & G_{e}(s)=\frac{5}{s^{2}+2 s+1} & G_{f}(s)=\frac{5}{s^{2}+2 s+0.75}
\end{array}
$$

Two separate dimensions of variation are used: one is a variation of the $s^{0}$-term of the denominator polynomial with the other terms invariant; the other is a variation of the numerator polynomial. Varying the $s^{0}$-term in the denominator of $G(s)$ generates three different types of root (complex conjugated, double, or two distinct real roots) of the denominator polynomial, each of which gives a result in a qualitatively different way (under-, critically, or over-damped) of approaching the steady-state for a step response, as shown in Figure 4. Students might also discern that the steady-state value depends on the transfer function's limit-value when $s$ approaches zero, i.e. the ratio between the $s^{0}$-terms of the numerator and denominator. It is also apparent that the initial behaviour of the response function depends on the numerator polynomial. In later experimental tasks, results from the simulation of the step response of the above transfer-functions are used to help students to discern among qualitatively different experimental results. This latter case is an example of diachronic simultaneity (See Carstensen and Bernhard 2007, 2009, for a detailed discussion).

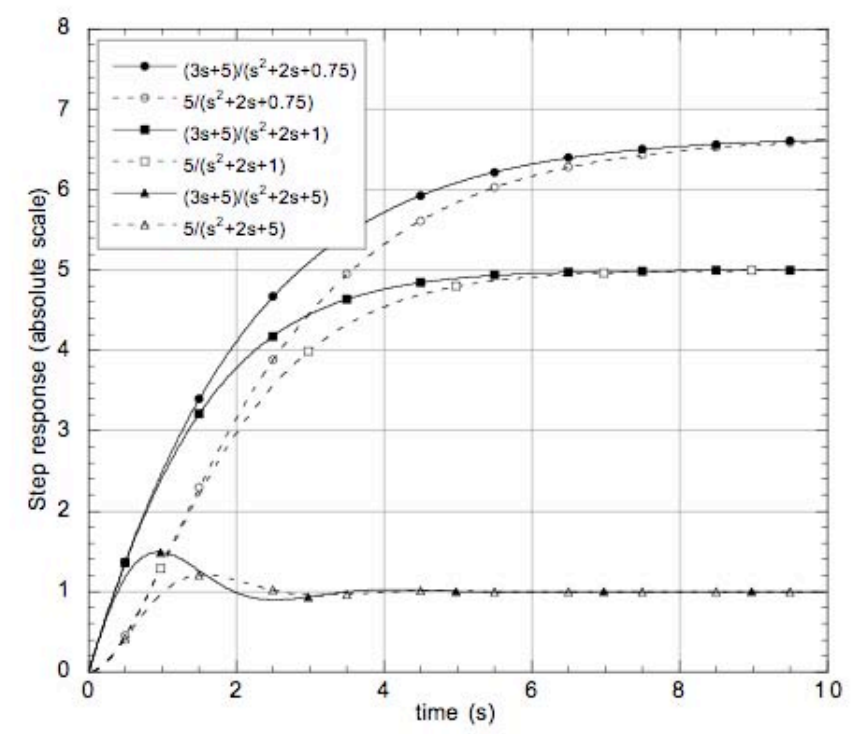

FIGURE 4. Step responses for the different transfer functions $G_{\mathrm{a}}(s)-G_{\mathrm{b}}(s)$. 


\section{Methodology for evaluating conceptual labs}

Marton and co-workers (Marton and Tsui 2004, Runesson and Marton 2002) distinguish between the intended object of learning, the enacted object of learning and the lived object of learning. The intended object of learning consists of the subject matter and the skills that the teacher or curriculum planner is expecting the students to learn. The enacted object is what it is actually made possible for the student to learn by the design of the learning environment. The lived object of learning is the way students see, understand, and make sense of the object of learning and the relevant capabilities that the students develop. Hence an evaluation of an educational design involves some kind of evaluation of, and comparison between, the intended, enacted, and lived object of learning. Qualitative as well as quantitative methods have been used in this evaluation. Space permits only a brief discussion of methodology used, but the references in this section provide more details and a deeper discussion.

In the mechanics part of this study we used the research-based conceptual test Force and Motion Conceptual Evaluation (FMCE) to investigate the functional understanding of mechanics attained by the students. The test uses multiple-choice questions to assess students' conceptual understanding of mechanics. The distractors (wrong answers) are carefully chosen to correspond with common-sense beliefs (misconceptions) as shown in the research literature on misconceptions. The multiple-choice format of FMCE makes it feasible to conduct controlled, large-scale educational studies. The FMCE has been shown, by its developers, to provide reliable and valid measures of students' conceptual understanding of basic Newtonian mechanics (Thornton and Sokoloff 1998). The FMCE-test was given to the students during one of the first lectures as a pre-test (one 45-minute lecture was set aside for this) and after the course was finished the test was re-administered as a post-test. In Figures $7 \mathrm{a}$ and $7 \mathrm{~b}$ the results from pre- and post-testing using FMCE are presented for different courses as 'absolute' values for different conceptual clusters. However, in Figures 8a and $8 \mathrm{~b}$ and in Table 1 the data is presented using a measure called normalised gain (Hake 1997). It's defined as $g=$ Gain/[Gain(max possible)] where Gain is the difference between pre- and post-test values.

My early data from the FMCE-test show that if we create lab-instructions that apply teaching strategies in line with variation theory, the students achieve better results than if the teacher adopts a non-conceptual approach. However, it is never possible to completely specify the enacted object of learning or the students' courses of action in the labs. This led to the following four interrelated questions:

i) In what different ways do the students approach the learning environment?

ii) How do the different approaches influence the students' enacted object of learning?

iii) Which aspects of the learning environment direct the students towards the intended object of learning?

iv) How can we further develop these aspects?

To help answer these questions, since 2001 I and co-workers have recorded students' courses of action using digital camcorders. The data have been used to detect typical interaction patterns and find evidence of, or to reject hypotheses on, the generality of these patterns (Jordan and Henderson 1995). In the analysis, we have been inspired by an emerging research practice that focuses on students' interactions in science and mathematics education.

Although the analytical approach adopted is influenced by ethnomethodology, conversation analysis, and situational approaches to learning and cognition (See, Lindwall 2008, for a review and more details), we have focused on central characteristics of learning environments to explore what the students do and which resources they use. Here, I present some reasons for the success of certain curricula. Since it is important to show not only verbal contributions, but also what the students are doing, some data are presented in the form of drawings resembling comic strips (see Figure 2) rather than traditional transcripts (Lindwall 2008). 
Students' lived object of learning in the electric circuit theory course has been analysed by a model called the 'learning of a complex concept' developed by Carstensen and Bernhard (2004, 2008, 2009; see also Bernhard et al. 2009). The idea behind this model is that knowledge is a whole, which is best represented as a complex made up of interrelated parts as illustrated in Figure 5. In this model "single concepts" are illustrated as nodes or "islands" that may be connected by links, while the links that students actually make (identified by analysing the lived object of learning), or are supposed to establish (identified by analysing the intended object of learning), are represented by arrows. The nodes in our model are found by looking for "gaps" (Wickman 2004) in the actions and conversations of students. A gap corresponds to a non-established link, and when a gap is filled and the students establish a relation between two nodes, this is represented by a link. The more links that are made, the more complete the knowledge.
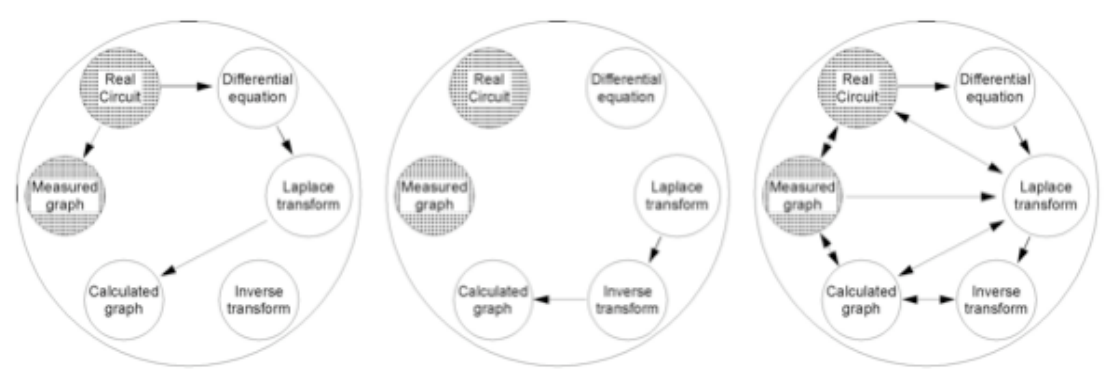

FIGURE 5. An example of an analysis of learning in a lab on the topic of transient response in electric circuits, using the model for learning a complex concept, illustrating: a) Student Benny's lived object of learning after the first part of the lab: b) Student Tess' lived object of learning at the same time; and c) Student Benny's and Tess' lived object of learning at the end of the lab work. The shaded circles are analytically attributed to the object/event 'world' and the unshaded circles represent the theory/model 'world'.

\section{Conceptual labs: History and results}

The empirical studies summarized in this paper have been conducted within a series of projects aimed at improving and investigating educational activities in physics and engineering education. The approach taken is similar to approaches described as 'designbased-research' or 'design experiment' (e.g. Brown 1992, Design-Based Research Collective 2003). According to Lo et al. (2004, p. 192) the "benefits of design experiments are that we will be able to contribute to theory development, and improve practice at the same time". Ference Marton has further extended these ideas with a stronger emphasis on teacher involvement in the study; he defines a learning study as "a systematic attempt to achieve an educational objective and learn from that attempt" (Marton [2001] cited in, Lo et al. 2004, p. 192).

Educational activities have been investigated in cycles of design, enactment, analysis, and re-design. A brief overview of the learning environments developed or studied in connection with this wider project of developing conceptual labs is shown in Figure 6. The different implementations serve as "natural experiments". Cobb et al. (2003, p. 9) note that "the successive iterations [of a design] play a role similar to that of systematic variation in experiments". 


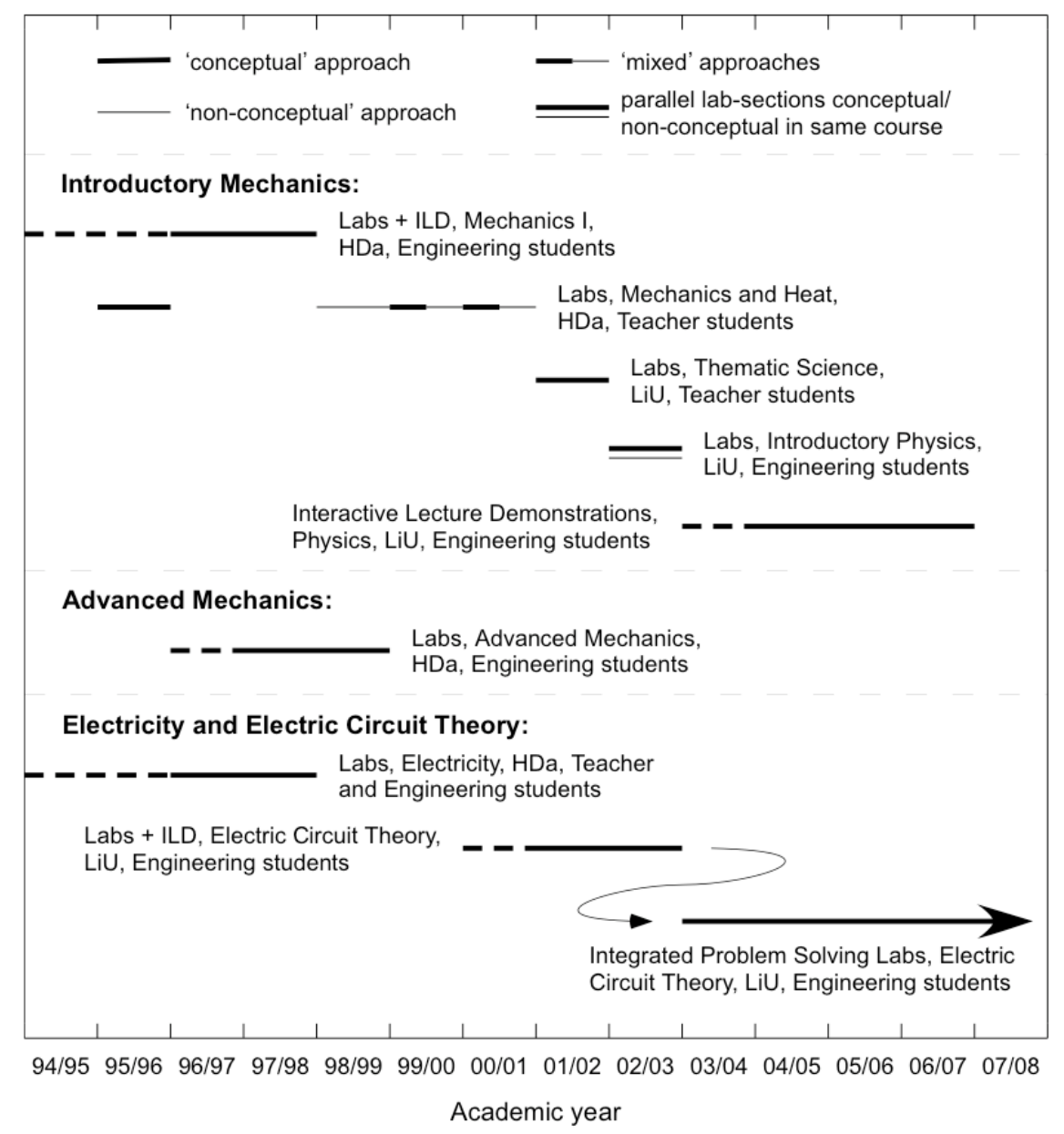

FIGURE 6. An overview of the learning environments developed and/or studied in connection with the larger 'project' of designing 'conceptual' labs and lecture demonstrations. The figure shows the type of course, its main student body, and the academic year in which the course was run. Abbreviations: HDa - Högskolan Dalarna (Dalarna University), LiU - Linköping University, ILD - Interactive Lecture Demonstrations. Dashed lines denote trials or reduced early versions of curricula.

In this section I focus on results from teaching introductory mechanics. The learning environment developed for advanced mechanics has been described elsewhere (Bernhard 1999).

As mentioned above, this wider project started in the 1994/95 academic year at Högskolan Dalarna (a small Swedish University) with the development of the first labs using probe-ware and conceptual learning approaches. Some labs were developed for learning mechanics as well as for studies of electricity. A more fully-fledged application was available the following year, with a set of labs for a course in mechanics and heat, and a course about electricity for trainee science teachers. However, at that time, no lab had been developed to deal with, for example, Newton's third law or the subject of rotary motion. Despite this, as shown in Figure 7b, the students on this course achieved good results in all conceptual areas covered by the FMCE-test, except Newton's third law (which was not included in the labcourse). In subsequent years the conceptual labs were developed into a full lab-course and included courses in engineering mechanics. The results are presented in Figure $7 \mathrm{~b}$ as 'absolute' values for different conceptual clusters in the FMCE-test. They show that the labs fostered good conceptual learning compared to traditionally taught courses (compare the 
results presented in Figure 7a), in line (as shown in Table 1) with some of the most wellknown innovative curricula developed in the USA, such as Workshop Physics.
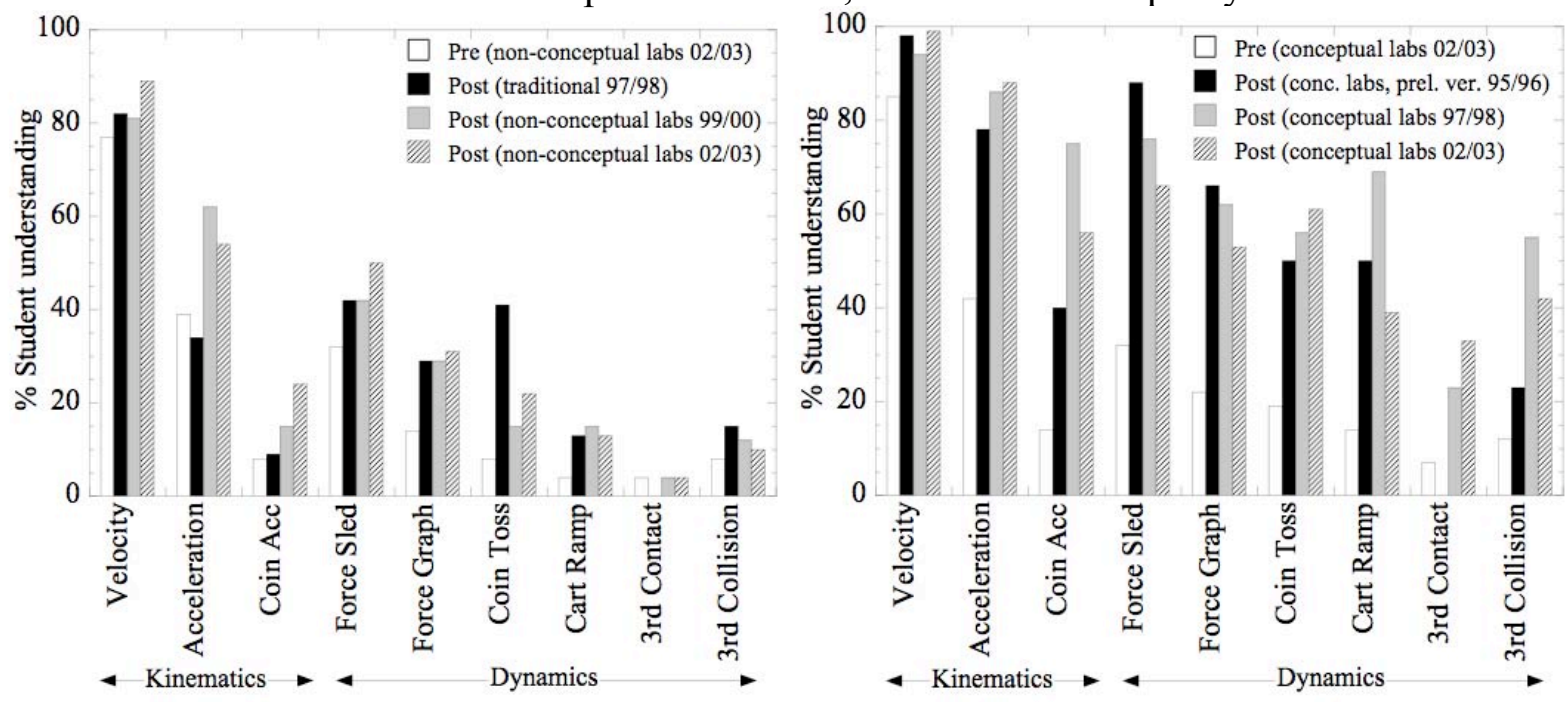

FIGURE 7. The results achieved, for different conceptual clusters, in the FMCE-test (Thornton and Sokoloff 1998) as a result of different mechanics courses. The data are shown as 'absolute' values from pre- and post-testing: a) data from traditionally taught university level courses in mechanics, b) data from mechanics taught with conceptual labs.

In my absence in the spring of 1999 the instructions were re-formulated as a formula verification approach. The instructor who made the changes believed that he had improved the labs. Figure 8 a compares, using normalised gain, the results of this changed curriculum with those for a course using the original conceptual approach. The differences in achieved learning are quite striking. This example demonstrates that probe-ware and computers do not automatically produce good learning results, but that the educational design is crucial. In the following two years, an experiment was carried out by another instructor. Some of the labs were returned to a conceptual format, thus providing valuable data for comparison (See Bernhard 2003, 2009a, for further details).

The project of developing conceptual labs was continued at Linköping University from the year 2000. The experiences and pedagogical ideas from the courses described above were used to develop conceptual labs for an electric circuit theory course for electrical engineering students. The course included advanced topics, such as the application of transform-methods (phasor, Fourier and Laplace) and Fourier-series. After some years, the conceptual labs were transformed into problem-solving labs, in which the problem-solving sessions and the original conceptual labs were merged into one type of session. Our analysis shows that this, together with the deliberate use of variation theory when designing tasks, has been especially successful in facilitating the learning of complex concepts (Bernhard and Carstensen 2002, Carstensen and Bernhard 2004, 2007, 2008, 2009). 

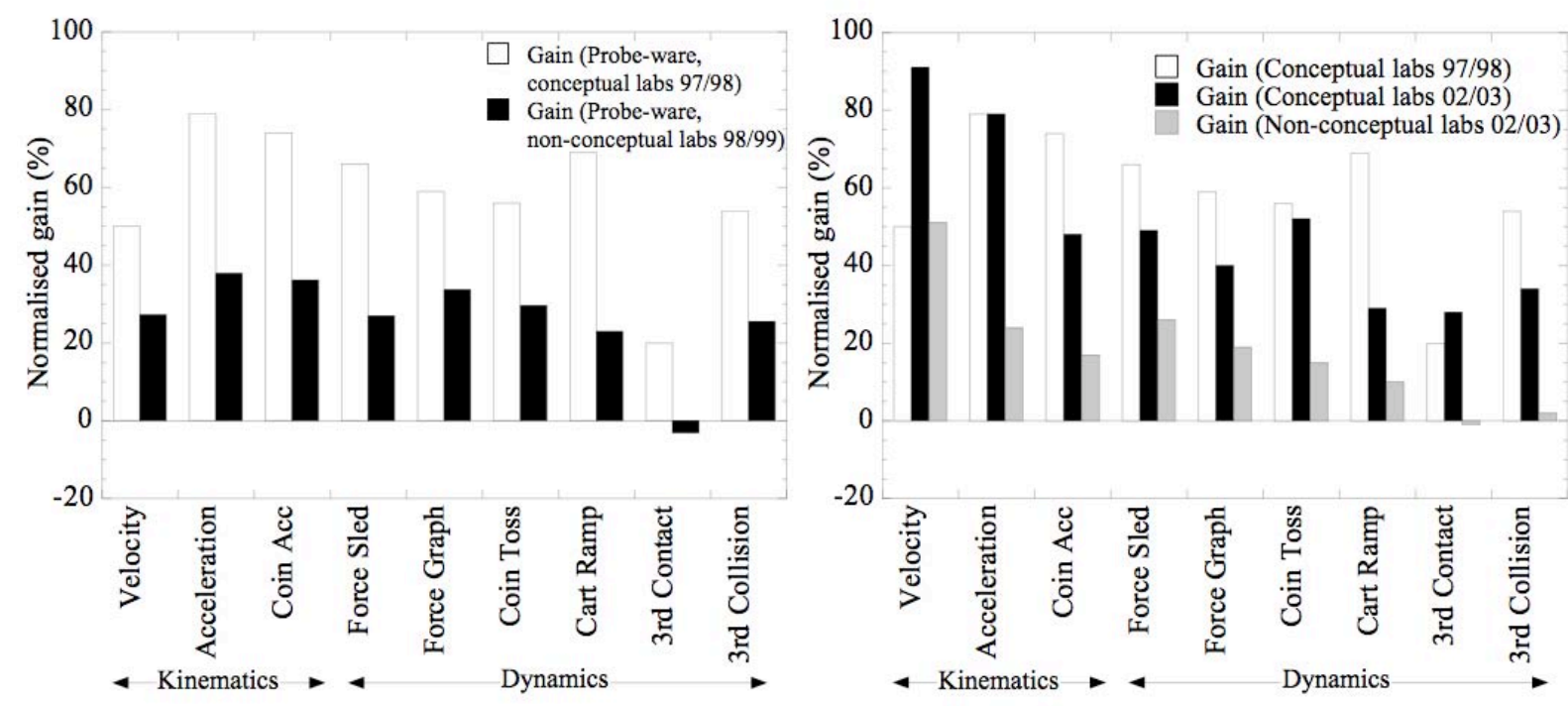

FIGURE 8. The results achieved according to the FMCE-test presented as normalised gains (see above): a) comparison of results obtained from two courses in which the same probeware technology was used in labs, but different educational approaches were adopted, b) comparison of results obtained by students participating in the same physics course, but different lab-sections. The test scores from the course using conceptual labs in 1997/98 are also included as a comparison.

Some years later, in parallel with designing an experiment relating to learning electric circuit theory, original conceptual mechanics labs were further developed, first in the context of a thematic education for future science teachers (academic year of 2001/02) and then, in the next year, by offering an alternative lab-course within a physics course for engineering students. In both cases a sub-set, consisting of four 4-hour labs, was offered during which students' courses of action were recorded on video. In the case of the engineering students, all of them participated in the same lectures and problem-solving sessions, so the only difference in teaching was the $16 \mathrm{~h}$ of labs. Figures 7a, 7b ('absolute' values) and $8 \mathrm{~b}$ (normalised gain) show the differences in conceptual understanding, according to the FMCE-test. Figures 7a and $7 \mathrm{~b}$ present pre- and post-test data in absolute values, and it can be seen that there were negligible differences in students' pre-conceptions. Although a full set of conceptual labs was not used, and the only difference between groups was that one did, and one did not, participate in $16 \mathrm{~h}$ of conceptual labs, the students who had attended the conceptual lab sessions clearly out-performed the other students, who had participated in a different set of labs, on the test.

An analysis of video recordings from the conceptual labs showed that students' courses of action ('lived object of learning') are framed by encounters with the instructions, the technology, the teacher, and other students. When using the technology, students receive immediate feedback. In the process of constructing graphs they can see when they make mistakes (as shown in Figure 2). Students intertwine different interpretative resources as well as different experiential domains, such as graphical shapes, with narrative accounts of past actions. Learners must focus on the central aspect of the graph and, in order to complete the assignments, they have to make certain conceptual distinctions. The instructions for the task specify the process and the variance and invariance in the learning space. In order to solve the tasks successfully, the students have to deal with certain concepts in certain ways. Teachers not only design the learning environment, choose the technology and write the instructions, but also support students' activities in the lab, including encouraging students to shift their attention to central features of the graph while down-playing less important aspects. Students 
have a common perspective on the graph and negotiate their different interpretations of the graphical representation, experiment, and subject matter. Discussions are made an important component of the process of solving the task. It should be noted that the technology is present in all encounters. A more detailed analysis, than space in this paper permits, is or will be presented elsewhere (Bernhard 2009c, Lindwall 2008, Lindwall and Lymer 2008).

\begin{tabular}{|l|l|l|}
\hline $\begin{array}{l}\text { Teaching } \\
\text { Method/Course }\end{array}$ & $\begin{array}{l}\text { Norm. Gain } \\
\text { (FMCE) }\end{array}$ & Reference \\
\hline Traditional (USA) & $16 \%$ & $\begin{array}{l}\text { Saul and Redish } \\
\text { (1998) }\end{array}$ \\
\hline $\begin{array}{l}\text { Non-conceptual labs } \\
\text { 2002/03 (Sweden) }\end{array}$ & $18 \%$ & Bernhard (2005) \\
\hline $\begin{array}{l}\text { Workshop physics } \\
\text { (USA) }\end{array}$ & $65 \%$ & $\begin{array}{l}\text { Saul and Redish } \\
(1998)\end{array}$ \\
\hline $\begin{array}{l}\text { RealTime physics } \\
\text { (secondary } \\
\text { implementation, USA) }\end{array}$ & $42 \%$ & Wittman (2002) \\
\hline $\begin{array}{l}\text { ILD (secondary } \\
\text { implementation, USA) }\end{array}$ & $26 \%$ & Redish (2003) \\
\hline $\begin{array}{l}\text { Conceptual labs 1997/98 } \\
\text { (Sweden) }\end{array}$ & $61 \%$ & Bernhard (2005) \\
\hline $\begin{array}{l}\text { Conceptual labs } \\
\text { (reduced set) 2002/03 } \\
\text { (Sweden) }\end{array}$ & $48 \%$ & $\begin{array}{l}\text { Bernhard } \text { et al. } \\
\text { (2007) }\end{array}$ \\
\hline \begin{tabular}{l} 
ILD 05/06 (Sweden) \\
\hline
\end{tabular} & $37 \%$ & \\
\hline
\end{tabular}

TABLE 1. Learning gains for different courses in mechanics as measured by the FMCE-test (Thornton and Sokoloff 1998).

A variant of conceptual labs is the interactive lecture demonstration (ILD) (Bernhard et al. 2007, Thornton 1997). An ILD has some similar features to conceptual labs, including the use of probe-ware and specially designed tasks; but an ILD is performed in a lecture format in front of an audience. It differs from a common demonstration in its use of specially designed tasks and worksheets. The learning gains, as measured by FMCE and shown in Table 1, are not as high as for a well-implemented conceptual lab sequence. However, the gains are greater than for a traditionally delivered course and, therefore, ILDs are an interesting alternative. Furthermore, there is an economic advantage of using ILDs since only one set of equipment is needed and the staffing cost is lower than for a traditional lab, and therefore ILDs are an interesting alternative.

\section{Discussion and conclusion}

In this series of projects, courses in mechanics and electric circuit theory, introductory as well as advanced, have been developed and studied. The projects have been put into practice at two different Swedish universities, with different teachers, and with different groups of students (engineering and trainee teachers). The conceptual labs have been organised in different ways: as labs, as problem-solving labs (integrating problem-solving and lab sessions), and as interactive lecture demonstrations (the labs taken to the lecture hall). In all cases, except for the case when labs using probe-ware were implemented as formula verification labs 
(Bernhard 2003), good learning results were achieved, as demonstrated above (See also Bernhard 2001, for long-time learning effects).

As mentioned previously, the development of conceptual labs was originally inspired by the approaches taken in RealTime Physics (RTP) (Sokoloff et al. 2007, Sokoloff et al. 1998). RTP has had great success in improving student learning at its primary development sites in the USA, but this and other research-based curricula have often been less successful following transfer to secondary implementation sites, although still far better than traditionally taught courses (Wittman 2002, see Table 1). Many tasks in my design of conceptual labs for introductory mechanics courses are similar to those developed for RTP. However, I have not simply transferred a Swedish translation of RTP. Instead, some tasks from RTP have been selected, adopted and adjusted to suit a different course structure and different culture. In addition, for some courses in advanced mechanics and engineering electric circuit theory there were no similar tasks in RTP - so tasks were designed "from scratch". Table 1 shows that my and co-workers results compare very well with different implementations of research-based curricula. I claim that one reason for our success is that our designs and re-designs are not ad hoc, but based on a theory of learning: variation theory.

Recently, other work in science and engineering based on variation theory has begun to appear. In several papers by, for example, Duncan Fraser, Cedric Linder and co-workers (Fraser et al. 2006, Fraser and Linder 2009, Linder et al. 2006) examples are provided from chemical engineering, process dynamics and physics. Thuné and Eckerdal (2009) have used the notion of variation to design learning activities in computer programming. The examples in these papers, together with our results, provide evidence of successful designs in engineering education using variation theory.

The findings show, through examples from many different courses, that properly designed labs, or lab-like learning environments, can provide a good environment for insightful learning. I conclude that all these results support the notion that variation theory is valuable in such a development. It would be an exciting task for the engineering education community, as well as the engineering education research community, to "engineer" (cf. Dewey 1922/1983) learning environments for insightful learning in other areas of engineering education.

\section{Acknowledgements}

In conducting the projects described in this paper I have been supported by, and co-operated with, many colleagues. I have also benefited from valuable discussions with many colleagues and I'm especially grateful to Anna-Karin Carstensen and Oskar Lindwall. This work has been supported by the former Council for Renewal of Higher Education, at the Swedish National Agency for Higher Education, through three different grants and by the Swedish Research Council.

\section{References}

Bernhard, J., 1999. Hands-on experiments in advanced mechanics courses. In: G. Born, H. Harreis, H. Litschke and N. Treitz eds. Hands on-Experiments in Physics Education. Duisburg: Didaktik der Physik, University of Duisburg, 175-177.

Bernhard, J., 2001. Does active engagement curricula give long-lived conceptual understanding? In: R. Pinto and S. Surinach eds. Physics Teacher Education Beyond 2000. Paris: Elsevier, 749-752.

Bernhard, J., 2003. Physics learning and microcomputer based laboratory (MBL): Learning effects of using MBL as a technological and as a cognitive tool. In: D. Psillos, K. P., V. Tselfes, E. Hatzikraniotis, G. Fassoulopoulos and M. Kallery eds. Science Education Research in the Knowledge Based Society. Dordrecht: Kluwer, 313-321.

Bernhard, J., 2005. Experientially based physics instruction - using hands on experiments and computers: Final report of project 167/96. Stockholm: Council for Renewal of Higher Education.

Bernhard, J., 2007. Thinking and learning through technology - Mediating tools and insights from philosophy of technology applied to science and engineering education. The Pantaneto Forum, 27.

Bernhard, J., 2009a. Critical conditions for insightful learning in the laboratory. Unpublished manuscript. 
Bernhard, J., 2009b. The role of technologies in the laboratory: Neglected aspects of research in science education. Unpublished manuscript.

Bernhard, J., 2009c. Making mechanics visible and learnable through technology and variation: A microanalysis of instructions and engineering students' practical achievement of understanding in labwork. Unpublished manuscript.

Bernhard, J., and Carstensen, A.-K., 2002. Learning and teaching electrical circuit theory. Paper presented at the PTEE 2002: Physics Teaching in Engineering Education, 5-7 June 2002 Leuven.

Bernhard, J., Carstensen, A.-K., and Holmberg, M., 2009. Investigating the model 'learning of a complex concept': The process of learning in a course in electric circuits. Paper presented at the PTEE 2009, 10-12 September 2009 Wroclaw.

Bernhard, J., Lindwall, O., Engkvist, J., Zhu, X., and Stadig Degerman, M., 2007. Making physics visible and learnable through interactive lecture demonstrations. Paper presented at the PTEE 2007, 25-26 October 2007 Delft.

Bowden, J., and Marton, F., 1998. The university of learning: Beyond quality and competence in higher education. London: Kogan Page.

Brown, A., 1992. Design experiments: Theoretical and methodological challenges in creating complex interventions in classroom settings. Journal of the Learning Sciences, 2, 141-178.

Carstensen, A.-K., and Bernhard, J., 2004. Laplace transforms - too difficult to teach, learn and apply, or just matter of how to do it. Paper presented at the EARLI sig\#9 Conference, 18-21 August 2004 Gothenburg.

Carstensen, A.-K., and Bernhard, J., 2007. Critical aspects for learning in an electric circuit theory course - an example of applying learning theory and design-based educational research in developing engineering education. Paper presented at the First International Conference on Research in Engineering Education, 2224 June 2007 Honolulu.

Carstensen, A.-K., and Bernhard, J., 2008. Threshold concepts and keys to the portal of understanding: Some examples from electrical engineering. In: R. Land, E. Meyer and J. Smith eds. Threshold concepts within the disciplines. Rotterdam: Sense Publishers, 143-154.

Carstensen, A.-K., and Bernhard, J., 2009. Student learning in an electric circuit theory course: Critical aspects and task design. European Journal of Engineering Education, 34(4), 389-404.

Cobb, P., Confrey, J., diSessa, A., Lehrer, R., and Schauble, L., 2003. Design experiments in educational research. Educational Researcher, 32(1), 9-13.

Cole, M., 1996. Cultural psychology: A once and future discipline. Cambridge, MA: Harvard University Press.

Design-Based Research Collective, 2003. Design-based research: An emerging paradigm for educational inquiry. Educational Researcher, 32(1), 5-8.

Dewey, J., 1983. Education as engineering. In: J. A. Boydston ed. The middle works of John Dewey, 1899-1924 (Vol. 13). Carbondale: Southern Illinois University Press, 323-328. (Original work published 1922)

Fraser, D., Allison, S., Combes, H., Case, J., and Linder, C., 2006. Using variation to enhance learning in engineering. International Journal of Engineering Education, 22(1), 102-108.

Fraser, D., and Linder, C., 2009. Teaching in higher education through the use of variation: Examples from distillation, physics and process dynamics. European Journal of Engineering Education, 34(4), 365-377.

Hake, R. R., 1997. Interactive-engagement vs traditional methods: A six-thousand-student survey of mechanics test data for introductory physics courses. American Journal of Physics, 66, 64-74.

Hammer, D., 1997. Discovery learning and discovery teaching. Cognition \& Instruction, 15, 485-529.

Ihde, D., 1979. Technics and praxis. Dordrecht: D. Reidel.

Ihde, D., 1991. Instrumental realism: The interface between philosophy of science and philosophy of technology. Bloomington: Indiana University Press.

Ihde, D., 2009. Postphenomenology and technoscience: The Peking university lectures. Albany: State University of New York Press.

Jordan, B., and Henderson, A., 1995. Interaction analysis: foundations and practice. The Journal of the Learning Sciences, 4(1), 39-103.

Laws, P., 1997a. A new order for mechanics. In: J. Wilson ed. Proceedings conference on introductory physics course. New York: Wiley, 125-136.

Laws, P., 1997b. Workshop Physics activity guide. New York: Wiley.

Linder, C., Fraser, D., and Pang, M. F., 2006. Using a variation approach to enhance physics learning in a college classroom. The Physics Teacher, 44(9), 589-592.

Lindwall, O., 2008. Lab work in science education: Instruction, inscription, and the practical achievement of understanding. Linköping: Linköping Studies in Arts and Science No. 426.

Lindwall, O., and Lymer, G., 2008. The dark matter of lab work: Illuminating the negotiation of disciplined perception in mechanics. Journal of the Learning Sciences, 17(2), 180 - 224. 
Lo, M. L., Marton, F., Pang, M. F., and Pong, W. Y., 2004. Toward a pedagogy of learning. In: F. Marton and A. B. M. Tsui eds. Classroom discourse and the space of learning. Mahwah, NJ: Lawrence Erlbaum, 189-225.

Marton, F., and Booth, S., 1997. Learning and awareness. Mahwah: Lawrence Erlbaum.

Marton, F., Runesson, U., and Tsui, A. B. M., 2004. The space of learning. In: F. Marton and A. B. M. Tsui eds. Classroom discourse and the space of learning. Mahwah: Lawrence Erlbaum, 3-40.

Marton, F., and Tsui, A. B. M., eds., 2004. Classroom Discourse and the Space of Learning. Mahwaw: Lawrence Erlbaum.

McDermott, L. C., 1997. How research can guide us in improving the introductory course. In: J. Wilson ed. Conference on the introductory physics course: On the occasion of the retirement of Robert Resnick. New York: John Wiley \& Sons, 33-46.

McDermott, L. C., and Redish, E. F., 1999. Resource letter: PER-1: Physics education research. American Journal of Physics, 67(9), 755-767.

Novak, J., 1979. The reception learning paradigm. Journal of research in science teaching, 16, 481-488.

Psillos, D., and Niedderer, H., eds., 2002. Teaching and learning in the science laboratory. Dordrecht: Kluwer.

Redish, E. F., 2003. Teaching physics with the Physics Suite. New York: John Wiley.

Rorty, R., 1991. Objectivity, relativism, and truth: Philosophical papers volume 1. Cambridge, UK: Cambridge University Press.

Runesson, U., 2006. What is it possible to learn? On variation as a necessary condition for learning. Scandinavian Journal of Educational Research, 50(4), 397-410.

Runesson, U., and Marton, F., 2002. The object of learning and the space variation. In: F. Marton and P. Morris eds. What matters? Discovering critical conditions of classroom learning. Göteborg: Acta Universitatis Gothoburgensis, 19-38.

Saul, J. M., and Redish, E. F., 1998. An evaluation of the Workshop Physics dissemination project. College Park: Dep. of Physics, University of Maryland.

Skolimowski, H., 1966. The structure of thinking in technology. Technology and Culture, 7(3), 371-383.

Sokoloff, D. R., Laws, P. W., and Thornton, R. K., 2007. RealTime Physics: active learning labs transforming the introductory laboratory. European Journal of Physics, 28(3), S83-S94.

Sokoloff, D. R., Thornton, R. K., and Laws, P., 1998. RealTime Physics. New York: Wiley.

Thornton, R. K., 1987. Tools for scientific thinking - microcomputer-based laboratories for teaching physics. Physics Education, 22, 230.

Thornton, R. K., 1996. Using large-scale classroom research to study student conceptual learning in mechanics and to develop new approaches to learning. In: R. F. Tinker ed. Microcomputer-based labs: Educational research and standards. Berlin: Springer, 89-114.

Thornton, R. K., 1997. Learning physics concepts in the introductory course: Microcomputer-based labs and interactive lecture demonstrations. In: J. Wilson ed. Proceedings conference on introductory physics course. New York: Wiley, 69-86.

Thornton, R. K., and Sokoloff, D. R., 1998. Assessing student learning of Newton's laws: The Force and motion conceptual evaluation and the evaluation of active learning laboratory and lecture curricula. American Journal of Physics, 66(4), 338-352.

Thuné, M., and Eckerdal, A., 2009. Variation theory applied to students' conceptions of computer programming. European Journal of Engineering Education, 34(4), 337-345.

Tinker, R. F., ed., 1996. Microcomputer-based labs: Educational research and standards. Berlin: Springer.

Wickman, P.-O., 2004. The practical epistemologies of the classroom: A study of laboratory work. Science Education, 88, 325-344.

Vince, J., and Tiberghien, A., 2002. Modelling in teaching and learning elementary physics. In: P. Brna ed. The role of communication in learning to model. Mahwah: Lawrence Erlbaum, 49-68.

Wittman, M., 2002. On the dissemination of proven curriculum materials: RealTime Physics and Interactive Lecture Demonstrations. Orono: Dep. of Physics and Astronomy, University of Maine.

Vygotsky, L. S., 1978. Mind in society: The development of higher psychological processes. Cambridge, MA: Harvard University Press. 